optically active and externally compensated forms of the isobase yielded an identical optically inactive diphenylethylene oxide, which therefore corresponds to the cis-configuration (iii), with a plane of symmetry (indicated by the broken line). $d$-Diphenylhydroxyethylamine, however, gave a strongly lævo-rotatory oxide, to which the trans-configuration (iv) must be assigned. It follows that the relative molecular configurations allocated to the above bases by Erlenmeyer in 1899 must be reversed, the base and the isobase being represented by (ii) and (i), respectively. We propose to explore further this valuable general method for determining the relative molecular configurations of such substances.

The stereoisomeric diphenylethylene oxides present several features of unusual interest :<smiles>c1ccc([C@@H]2O[C@@H]2c2ccccc2)cc1</smiles><smiles>[PH2+]c1ccccc1</smiles>

The trans-form (iv) is an example of the simplest type of cyclic structure which can give rise to dissymmetry of molecular configuration: it will be noticed that the assemblage of five single atoms carrying two identical radicals still displays axial symmetry, although a plane of symmetry is no longer present. These simple structural constituents may be compared instructively with the four single atoms and one group of the simplest known acyclic dissymmetric compound, chloroiodomethanesulphonic acid, that is, CHClI - $\mathrm{SO}_{3} \mathrm{H}$. The specific rotatory power of the $l$-form of the above oxide (iv), observed in absolute alcohol for sodium light, exceeds $-300^{\circ}$, while the corresponding value for $l$-isohydrobenzoin (its configurational analogue) is only $-92^{\circ}$ : thus, the optical effect of the 3-membered ring is strikingly apparent. The extraordinary stability of these well-defined crystalline oxides is in keeping with the views of Thorpe and Ingold on the effect of substituents in relieving the strain inherent in small rings.

Other compounds of the same general type which we are at present investigating exhibit an equally pronounced stability; among them, the cis-form of 2:3-dianisylethylene oxide has been obtained by the direct interaction of nitrous acid and the corresponding dianisylhydroxyethylamine, as well as from the same base by the general method indicated above. Details of these studies and of further work directed towards the preparation of optically active ethylene oxides, containing aromatic or aliphatic substituents, will be published elsewhere.

\section{JOHN READ.}

Ishbel G. M. CAMPBell.

The University,

St. Andrews.

Do Oceanic Plankton Animals Lose Themselves ?

RECENT researches into the behaviour of plankton animals in the sea as to their vertical movements from day to day indicate that light intensity is an important factor. The animals appear in Nature to be brought around an optimum intensity by some tropistic mechanism and, assuming this, there seems likely to be a lower limiting or threshold intensity below which no stimulation takes place. Such, indeed, appears to be the case at night with animals living in our shallower offshore waters, when, with the release of the light stimulus in darkness, they are free to roam anywhere and become evenly distributed throughout the water layers, within the limits of other controlling factors such as temperature and salinity This lower threshold intensity idea receives support from a paper published in 1926 by two Japanese workers, M. Tauti and H. Hayasi (Jour. Imper. Fisher. Instit., Tokyo, vol. 21, No. 4, p. 42), who found that if a light be projected at night vertically downwards into the water, fish swimming in numbers deeper in the water are only attracted individually to the light when by random movements they swim upwards into a certain threshold intensity.

In view of these observations, the suggestion arises whether certain plankton animals which normally live in light of moderate intensities near the surface, but are to be found also in the deep, dark layers of the open ocean, are not, so to speak, lost in these latter layers. Have they moved out of their normal light zone, perhaps at night, and reached layers at which the intensity is below the threshold, thus to be doomed to everlasting night until perchance by random movements one bright day they swim once more into the threshold intensity zone and are attracted upwards to their optimum intensity?

Marine Biological Association, Plymouth.

\section{Magic Square of Fifth Order.}

I venTURE to send you what I believe to be a very rare magic square of fifth order. Although there are more than 260,000 bordered squares of fifth order with the number 13 in the centre of the square, it seems a very rare thing indeed for any other number than 13 to be in the centre. I have not found any with the

\begin{tabular}{|c|c|c|c|c|c|}
\hline 23 & 20 & 10 & 4 & 8 & \\
\hline 22 & 2 & 16 & 18 & 7 & $36 / 29$ \\
\hline 14 & 13 & 17 & 6 & 15 & \\
\hline 5 & 21 & 3 & 12 & 24 & \\
\hline 1 & 9 & 19 & 25 & 11 & \\
\hline
\end{tabular}

usual proportion (39/26) between the Row of the Heart and the rest of the Row, and it was not until the proportion 36/29 arrived that I found it was possible to make one. I append the square. Subtracting each number from 26 will give the proportion $42 / 23$. I believe there are only two (not including inversions) with 17 in the centre of the square.

Barkston, near Grantham, Dec. 2.

J. C. Burnets.

\section{Legitimate Uncertainty.}

ADVANCE of inquiry into fundamental tracts of Nature is often perforce conducted by means of symbolism. The comprehensive character of the symbols counts for increase of knowledge, even though their physical interpretation is still shrouded in uncertainty. Thus it is that, for example, Prof. Eddington, on page 291 of "The Nature of the Physical World", amusingly sums up our present knowledge of electronic opera. tions inside atoms by saying: "Something unknown is doing we don't know what - that is what our theory amounts to". Similarly the sentences quoted from one of my books, at the end of a review on page 942 of NATURE for Dec. 21, should be understood, not as a hopeless and helpless admission of ignorance but as a scrupulously fair and cautious stage in the advance of knowledge ; for it is no gain to science to attempt the formulation of a nascent theory prematurely.

Lake, Salisbury.
Oliver Lodge.

No. 3140, VoL. 125] 